\title{
Application of Gas Protection Device in High Gas Mine
}

\author{
Bowen Cui \\ Shandong University of Science and Technology,Mining and Safety \\ engineering institute, ShanDong, QingDao,266590, China \\ email:Iulu8472@qq.com
}

\begin{abstract}
Key words: Gas drainage;Protection device; Mine goaf; Drainage pipeline
Abstract: Aiming at the characteristics of high gas coal seam hosting and the problem in the process of coal gas control, this article mainly focus on the research of the gas drainage technology in the goaf and the coupling characteristics with the explosion proof device. First of all, it describes the comprehensive gas drainage technology in mine, then put forward a new gas control device, and developed the corresponding supporting equipment and materials, which applied in mine, results show that the technology can solve the gas drainage tube's hidden trouble of electrostatic burst, ensure the coal mine's continuous safety production.
\end{abstract}

\section{Introduction}

Mine gas is one of the most harmful gases which threat to coal mine safety production, it is also clean and efficient energy and high-quality chemical raw materials. Gas drainage can not only reduce the amount of mine gas emission, prevent gas explosion and gas outburst, and the out-gas can be used as a clean energy, which can reduce environmental pollution.

In our country, the superior occurrence of coal seam is gradually decreasing, the intensity of coal mining is increasing[1], mining environment is getting more and more complicated, coal and rock dynamic disasters happens unpredictable, all those circumstances are seriously threating the safety of coal production. Coal roadway tunneling faces are the main places of coal and rock dynamic disaster, because the coal and rock excavation is often happened that relatively unknown, which makes the accident prevention and control a great difficulty. The conventional ventilation dilution method can not solve the problem of coal mining safety in high gas face.

In view of the low permeability coal seam characteristics and "Ventilation and Three Preventions" safety and quality standardization requirements, we should build gas drainage system[2], but the drainage environment is complex, drainage pipe with high mine gas, friction generated static electricity through the pipe wall which induce combustion of methane pipeline, resulting in some pipes burst. Taking the above reasons into account, we propose a protective gas drainage device, which can effectively ensure the safe production of mine, and has broad application prospects.

\section{Prevent and control technology of mechanized caving face}

The mainly emission of methane in mechanized face happened in two processes - coal and cut[3]. From years of statistical data analysis, the main sources of gas in mechanized mining face are: (a) Emission of gas when coal cutting machine coal drop, emission of it approximately account $10 \%-20 \%$ of the total. During mining this part gas mainly rely on ventilation to solve. This part of the gas sharply emission, which need for native media pre-pumping to reduce the gas content in coal. (b) Emission of goaf gas, emission of it is a high concentration of approximately account $80 \%$. For these large emission and high concentrations of gas, it can only be handled by the method of extraction. So methane gas drainage in the process of governance is particularly important. Based on this, we came up with gas drainage guards, which has important practical significance.

\section{Goaf gas drainage}

Since mechanized coal face mainly from the mined-out area, and this part of the gas density is 
high and the emission is large, so gas manage area is the focus of prevention and control of mechanized coal face. But goaf gas drainage is difficult, in order to ensure the safety of fully mechanized coal face of production, we should make sure the requirement goaf have enough gas drainage capacity, ensure goaf gas not scattered outward, while ensuring residual coal mining empty area should not occur spontaneous combustion. According to the mine fully mechanized mining face, roadway layout and mining technology features[4] , using the drainage pipe drainage way, but the drainage environment is complex, drainage pipe with high mine gas, friction generated static electricity through the pipe wall which induce combustion of methane pipeline, resulting in some pipes burst. The proposed gas drainage guard in this paper can effectively prevent pipeline breaks and ensure safety in production mine.

\section{Gas protection device}

The front of the gas protection device provided a three-way emptying, emptying valves and valve closure[5], upper the drainage pipe, there are several metal pipe groundings connecting drainage pipes through flange, there also have drainage devices, which comprises a barrel, in the side of cylindrical, provided with a drainage pipe communicating into the water and drain, the bottom end of the cylinder body is fixed to the center of the guide seat, which fixed magnet and the attractive iron, there have several loat blocks fixed on it.

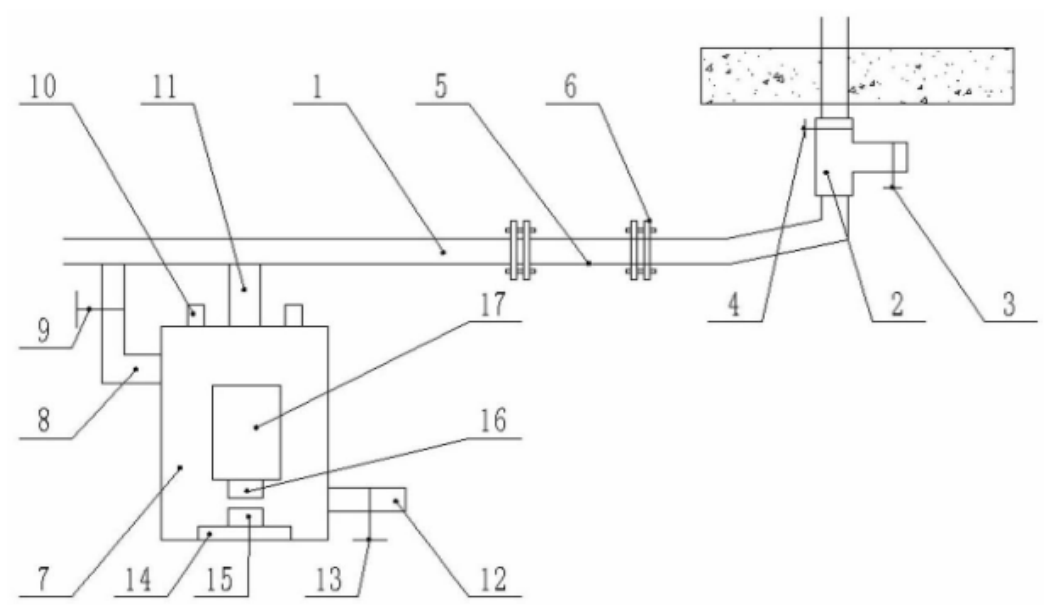

Figure 1. Gas protection device diagram

When we apply the gas protection device, the inlet valve and vacuum balance tube open, gas drainage pipeline can flows into the cylinder body through the water inlet pipe, the float block will rise and detach from the magnet. Inlet valve and the vacuum balance tube will close, then the pass valve opens, under the effect of hydrostatic pressure, the drain valve is opened, with the outflow of water, the float block drops, which lead inlet valve and the vacuum balance tube open again, vent valve and drain valve closed at atmospheric pressure, the float block position will return to the initial state, after the completion of gas drainage, we should stop the pump. In order to finish the process, we should open the drain valve firstly, then inhale fresh air flow from the drain valve, while closing the closure valve, when the gas density in the gas drainage chamber dropped to the minimum, turn off gas drainage pump. By setting the grounding metal pipe, the static electricity generated in the gas drainage process can be lead into the ground.

\section{Application}

We use the gas protection device proposed in this article into Shanxi Datong Coal Mine, after a period time of applying, the device achieved better results in the mining face. It not only inhibits the gas not scat out of the goaf, but also ensures the laid of pipelines did not rupture, make sure the safety of mine production. 


\section{Conclusion}

Due to its features of long-term stability,, firm structure, moisture , proof, work over a wide range temperature, the gas guard system has been widely used in mine excavating, solve the current situation of the prevalence gas accident, it can also maximize the protection of personnel and equipments' safety, achieve safe production of coal mines ,which has a significant developed value.

\section{References}

[1] Chuangxin Lv. Application of Fiber Grating Dynamometry Bolt in Coal Mine Tunnel Surrounding Rock Monitoring[J]. Chinese Science and Technology Paper,2015,8(16):1751-1760.

[2]Qingshun Meng. Discussion on Coal Mine Safety Management Innovation[J]. Coal Engineering, 2013 (2):138-140.

[3] Ping Lu, Zegong Liu. High Gas Coal Mining Face Relief Roof Stratum Drainage Experimental Research[J]. Mechanics in Engineering,2003,(4):53-56.

[4] Li Li. Application of High Gas Underground Mechanized Caving Face Gas Prevention Technology[J]. Coal Engineering,2012,(5):62-64.

[5] Yun Li, Jianwu Yang, Xinping Ma, Wen Sun, Junlong Wang. Gas Drainage Guard System[P].China:CN 104533509A,2015,04,22. 